\title{
Yoğun Bakım Hastalarında Deliryum ve Yaşam Modeli Doğrultusunda Bakımı
}

\author{
Delirium in Intensive Care Unit Patients and Care in the Accordance \\ with the Model of Living
}

\author{
Aysel ÖZSABAN*, Rengin ACAROĞLU**
}

İletişim/Correspondence: Aysel ÖZSABAN Adres/Address: İstanbul Üniversitesi Florence Nightingale Hemşirelik Fakültesi, Abide-i Hürriyet Caddesi, Şişli/İstanbul Tel: 021244000 00/27134 Fax: 02122244990 E-mail: ayselates87@gmail.com

\begin{abstract}
$\ddot{O} Z$
Deliryum; ani başlayan, bilişsel işlevlerin bozulması, bilinç durumunda değişiklik, dikkat bozuklukları, artmış ya da azalmış psikomotor aktivite ve uyku-uyanıklık döngüsünün düzensizliği ile karakterize geçici, organik mental bir sendromdur. Yapılan çalışmalar, yoğun bakım ünitesinde yatan hastalarda deliryum riskinin yüksek olduğunu ve buna bağlı olarak mortalite ve morbidite oranlarının arttığını, hastanede kalış süresinin uzadiğını ve tedavi edilmediğinde hastada fonksiyon kayıplarına yol açtı̆̆ııı göstermektedir. Hasta bireyin yaşamını tehdit eden deliryum sorununun tanılanması ve risk altında olan hastalarda önleyici girişimlerin erken dönemde uygulanmasl ve tedavi edilmesinde yoğun bakım hemşireleri anahtar konumdadır. Bu derlemede, yoğun bakım ünitesinde deliryum gelişsen hastaların bakımının bir hemşirelik modeli rehber alınarak, hemşirelik süreci doğrultusunda irdelenmesi amaçlandl.
\end{abstract}

Anahtar Kelimeler: Deliryum, hemşirelik bakımı, yoğun bakım ünitesi, yaşam modeli.

\section{ABSTRACT}

Delirium is a transient organic mental syndrome generally characterised by sudden onset of cognitive disturbances, altered level of consciousness, impaired attention, increased or decreased psychomotor activity and irregular sleep-wake cycles. The studies indicated that delirium is associated with prolonged hospital stays, increased morbidity and mortality and loss of function for the intensive care unit patients. Intensive care unit nurses are key position for assessment of delirium problem, implementation of preventive interventions and treatment of delirium. In this article, nursing care of patients who developed delirium in the intensive care unit is examined in accordance with the nursing process that based a nursing model. Key Words: Delirium, nursing care, intensive care unit, living model.

\section{GíRiş}

Yoğun bakım ünitesi (YBÜ)'nde yatan hastalarda fizik ortam, hastanın tıbbi tanısı ve uygulanan tedavilere bağlı olarak psikolojik ve/veya fizyolojik, kalıcı ya da geçici komplikasyonlar ortaya çıkabilir. Bu komplikasyonların belirlenmesi ve önlenmesine ilişkin çalışmalar, yoğun bakım hastalarında ciddi hasarlara ne- den olabilen sorunlardan birinin \%16-89 oranında görülen deliryum olduğuna işaret etmektedir (Bruno ve Warren 2010; Ely ve ark. 2004; Krahne, Heymann ve Spies 2006). Deliryum; ani başlayan, bilişsel işlevlerin bozulması, bilinç durumunda değişiklik, dikkat bozuklukları, artmış ya da azalmış psikomotor aktivite ve uyku-uyanıklık döngüsünün düzensizliği ile karak-

\footnotetext{
* Arş. Gör. Msc. İstanbul Üniversitesi Florence Nightingale Hemşirelik Fakültesi, ** Prof. Dr. İstanbul Üniversitesi Florence Nightingale Hemşirelik Fakültesi
}

Yazının gönderilme tarihi: 03.04.2014

Yazının basım için kabul tarihi: 21.05.2015 
terize geçici, organik mental bir sendromdur (Akınc1 ve Şahin 2005; Krahne ve ark. 2006). Hastalarda ortaya çıkan bu mental değişimlerin yoğun bakım sendromu, yoğun bakım psikozu, akut konfüzyon durumu, akut beyin sendromu gibi farklı terimlerle ifade edilmesi, deliryumun yakın zamana kadar yoğun bakım hastaları için beklenen bir durum olarak algılanmasına ve gerekli önemin verilmemesine yol açmıştır (Akınc1 ve Şahin 2005).

Hastanın YBÜ'ne kabulünden sonra ortalama ikinci veya üçüncü günde ortaya çıkan deliryum, ortalama üç-dört günde sonlanmakla birlikte nadir de olsa 60 gün sürebilmektedir (Ely ve ark. 2001). Deliryum genellikle üç farklı tipte ortaya çıkmaktadır. Hipoaktif deliryumda, duyarlılık ve psikomotor aktivite azalmış, hastalar konfüze ve yorgun görünümdedir. Hiperaktif deliryumda, hasta uyarılara aşırı duyarlıdır ve psikomotor aktivitesi artmıştır, kateterlerin çekilmesi gibi tıbbi aletlerden kurtulma çabası, ajitasyon sık görülen belirtilerdir. Mikst tip deliryumda ise; hasta gün içinde hem hiperaktif hem de hipoaktif belirtiler gösterebilmektedir (Devlin ve ark. 2008; Küçük ve Kaya 2011).

Hastalarda deliryum riski / varlığının değerlendirilmesi, önleyici / tedavi edici girişimlerin erken dönemde başlatılarak geri dönüşümsüz aşamaya gelmesinin ya da yaygın hasar bırakmasının önlenmesi tüm sağlık ekibi üyelerinin işbirliğini gerektirir (Küçük ve Kaya 2011). Bununla birlikte, hastaları sürekli gözlemleyerek değişiklikleri erken dönemde fark eden ekip üyeleri olarak hemşireler, bu süreçte anahtar rol üstlenirler (Schuurmans, Duursma ve Shortridge- Baggett 2001; Webb, Carlton ve Geehan 2000). Ancak yapılan çalışmalar YBÜ'de çalışan hemşirelerin, hastaları deliryum varlığı/riski açısından tanılamada yetersiz kald1ğını göstermektedir (Rice ve ark. 2011; Schuurmans ve ark. 2001). Ülkemizde 17 YBÜ'sinde çalışan 301 hemşire ile yürütülen bir çalışmada da benzer sonuçlara ulaşılmış ve hizmet içi programlarda konuya yer verme oranının oldukça düşük olduğu belirlenmiştir (Ateş 2012). Bu doğrultuda, derlemede, YBÜ' nde yatan hastaların değerlendirilmesi, izlenmesi ve bak1- mında, Yaşam Modeli rehberliğinde uygulanan hemşirelik sürecinde, deliryum ile ilişkili bilgilere üzerinde durulmuştur.

\section{DELİRYUM RİSKİ/ VARLIĞINDA HASTA BİREYIN BAKIMI}

\section{Tanılama}

Yoğun bakım ünitesine kabulü yapılan hasta bireyden gözlem, görüşme ve fizik muayene yöntemleri ile ayrintılı veri toplanarak kabul tanılamas1 yapılır. (Acaroğlu, Şendir ve Kaya 2012; Weber ve Kelly 2010). Ayrıca bu aşamada hasta ve ailesi bilgilendirilir ve tanılama sürecine dahil edilir (Flagg, McDowel ve Buelow 2010).

Hemşirelik öyküsünde; bireysel özellikler, mevcut şikayeti/ başvurma nedeni, öz geçmişi (alkol, sigara, madde kullanımı, yaşam biçimi, sağlık uygulamaları) ve soy geçmişi sorgulanırken, aynı zamanda demans varlığı, geçmiş deliryum öyküsü, görme/ işitme sorunları, hareketsizlik gibi deliryumun kontrol edilemez risk faktörleri dikkatle değerlendirilir (Truman ve Ely 2003). Aynı zamanda hasta bireyin yüz ifadesi, davranış, duygulanım, konuşma, düşünme süreci, algılar1, bilişsel becerileri, postürü, vücut hareketleri, kişisel hijyen ve giyimi gözlenmelidir. Görüşme sırasında mevcut deliryum tanılama araçlarından yararlanılması somut veri elde etmeye olanak sağlar.

Günlük Yaşam Aktivitelerinin değerlendirilmesinde;

- Bilişsel becerileri; bilinç seviyesi (konfüzyon, oryantasyon bozukluğu vb.), konsantrasyon, uzak ve yakın bellek, yargılama, muhakeme yeteneği, görme, işitme vb. duyusal algıları ve sorunları, ağrı varlığ1 (Krahne ve ark. 2006; Webb ve ark. 2000; Weber ve Kelly 2010),

- Mental durumu, bireyin kendinin farkında olup olmadığı, anlama ve kavrama becerileri, konuşma şekli (çok, hızlı, anlamsız vb.), motor aktiviteleri (stereotipi, mannerizm vb.), duygu durumu (ağlama, gülme), göz teması kurma durumu, düşünce süreci, algısı (halüsinasyon vb.) (Derby 2011; Nur- 
sing Management of Delirium 2013; Tabet ve Howard 2009).

- Solunum güçlüğü, oksijen tedavisi gereksinimi, trakeostomi ya da mekanik ventilasyon varlığı (Rompaey ve ark. 2009; Stuck, Clark ve Connelly 2011),

- Enteral ve parenteral beslenme tüpleri vb. beslenmede yardımcı araç-gereç kullanımı, malnutrisyon varlığ1 (Derby 2011; Tabet ve Howard 2009; Rompaey ve ark. 2009),

- Üriner kateterizasyon, rektal tüp, sıv1- elektrolit dengesizlikleri, böbrek ve bağırsak problemlerinin varlığı (Schuurmans ve ark. 2001; Rompaey ve ark. 2009),

- Deri bütünlüğü, tonüsü, nemi, ağız mukozasının durumu, (Conley 2011; Webster 2011),

- Vücut sıcaklığına ilişkin değişimler ya da sorunlar (Nursing Management of Delirium 2013; Rompaey ve ark. 2009),

- Hareket düzeyi, motor aktiviteleri, hareketi etkileyebilecek sorunlar (Rompaey ve ark. 2009; Tabet ve Howard 2009),

- Bilinci açık olan bireyin ilgi alanları ve hobileri (Fong, Tulebaev ve Inouye 2009),

- Beden imajını etkileyebilecek organ kayıplarının varlığ 1 , kendi görüntüsünü nasıl algıladığ (Cole 2004),

- Uyku düzeni, alışkanlıkları, ajitasyon belirtileri tan1lanır (Stuck ve ark. 2011; Tabet ve Howard 2009; Webb ve ark. 2000).

$\mathrm{Bu}$ veriler toplanırken, yaşam aktivitelerini etkileyen biyofizyolojik, psikolojik, sosyokültürel, çevresel ve politikoekonomik faktörler dikkate alınmalıdır (Conley 2011; Derby 2011; Flagg ve ark. 2010; Weber ve Kelly 2010; Webster 2011).

Fizik muayenede özellikle kranial sinirler, motor ve serebellar fonksiyonlar, duyusal fonksiyonlar ve refleksler değerlendirilir (Weber ve Kelly 2010).

Kabul tanılamasında gözlem, görüşme ve fizik muayenenin yanı sıra deliryum tanılama araçları kullanılarak elde edilen objektif ve subjektif veriler, hasta bi- reyin deliryum riski/ varlı̆̆ına ilişkin önemli ipuçları sağlayacaktır (Devlin ve ark. 2008; Rice ve ark. 2011). Veriler deliryum riski/ varlığına işaret ediyorsa değerlendirme, belirli aralıklarla tekrarlanan odaklanmış tanılama ile sürdürülür (Burge, Kent, Verdon, Voogt ve Haines 2010). Ayrıca hastada ani mental değişiklikler, açıklanamayan konfüzyon, bağırma, huzursuzluk, gelişmekte olan hipoaktivite gözlendiğinde deliryum tanılama araçlarından yararlanılarak acil tanılama yapılmalıdır (Burge ve ark. 2010; Rice ve ark. 2011; Truman ve Ely 2003).

\section{Hemşirelik Tanısı}

YBÜ'ye yatan hastalarda bireysel özelliklere özgü farklılık göstermek ile birlikte, deliryum risk faktörlerine sahip ya da deliryum gelişen hastalarda sık karşılaşılan NANDA-I (North American Nursing Diagnosis Assosciation-International) hemşirelik tanılar1 "Düşünme Sürecinde Bozulma, Sosyal Etkileşimde Bozulma, Uyku Örüntüsünde Bozulma ve Travma Riski” olarak sıralanabilir (Carpenito- Moyet 2012).

\section{Planlama}

\section{Düşünme Sürecinde Bozulma}

Tanımlayıcı özellikler: Soyutlama, problem çözme, bellek yetersizliği şeklinde ortaya çıkan bilişsel yetersizlikler, odaklanabilme yeteneğinde azalma, oryantasyon bozukluğu, konfüzyon, anksiyete, ritualistik davranışlar, sanrılar, halüsinasyonlar,

Ilişkili faktörler: Uyaran eksikliği/ fazlalığı, uyku örüntüsünde bozulma, anksiyete, korku, siv1- elektrolit dengesi bozuklukları, alkol ve madde yoksunluğu.

Amaç/ Beklenen hasta sonuçları: Gerçekle bağlantı kurması artacak, yere, zamana kişiye oryante olacak, ajitasyonu azalacak, yaşam aktivitelerini sürdürmede bağımsızlık düzeyi artacak,

\section{Hemşirelik girişimleri:}

- Empatik, saygın, güven verici ve yarar sağlayıcı terapötik bir ortam sağlanarak hasta bireyin bütünlük duygusu desteklenir, 
- Yaşam aktivitelerine ilişkin bakım uygulamalarına katılımı sağlanır,

- Takvim ve saat hastanın görebileceği bir alana yerleştirilerek yer ve zaman

- oryantasyonu sürdürülür,

- Hasta bireyin gözlük, işitme cihazı gibi duyusal gereksinimleri ilk firsatta giderilerek algılaması düzeltilir,

- Evden kişisel eşyaları ve alışık olduğu objelerin getirtilmesi, aile üyelerinin ziyaret etmesi sağlanarak anlamlı ve yeterli duyusal uyaran sağlanır,

- Beslenme, kişisel hijyen, uyku gibi günlük aktivitelerine ilişkin gereksinimler mümkün olduğunca aynı saatlerde karşıllanmaya çalışılır,

- Halüsinasyon ve sanrılarına ilişkin; hasta birey ile kısa, kolay cümleler kullanarak, yavaş ve anlaşılır konuşularak güven verici ilişki kurulur, duyguları$\mathrm{n} 1$ ifade etmesi sağlanır, halüsinasyon ve sanrıları onaylanmadan gerçeğe dönmesi için desteklenir,

- Özellikle ajite hasta bireyler yalnız birakılmayarak, gevşeme teknikleri

- (dikkati başka yöne çekme, solunum egzersizleri vb.) ile sakinleştirilir,

- Çevredeki resimler, dekorasyonlar, televizyon, radyo, çağrı sistemleri, aletler vb. yanlış algılamalara neden olabileceğinden mümkünse en aza indirilir ve bunların ne olduğu hastaya açıklanır,

- Ajitasyon, huzursuzluk, kateterleri çekme vb. davranışlar sergileyen hasta bireylere uygulanan fiziksel kısıtlamaların nedeni anlayacağı bir biçimde açıklanır (Carpenito-Moyet 2012; Day, Higgins ve Keatinge 2011; Nursing Management of Delirium 2013; Townsend 2011).

\section{Sosyal Etkileşimde Bozulma}

Tanımlayıcı özellikler: Apati, umutsuzluk ya da güçsüzlük hisleri, fonksiyonel yetersizliğin tanımlanmas1, sosyal izolasyon, yüzeysel ilişkiler kurma, diğer insanlardan kaçınma, yanlış anlaşılma duygusunun olmas1.

İlişkili faktörler: Şüphecilik, mantıksal olmayan fikirler, yüksek düzeyde anksiyete, sanrılar, halüsinasyon- lar, dezorganize düşünme, depresif davranışlar, alışılagelen sosyal örüntülerin değişimi.

Amaç/Beklenen hasta sonuçları: Hasta umutsuzluk ya da güçsüzlügü ifade edecek, sosyal ilişkilere cevap verecek, hasta birey, ailesi ve sağlık ekibi üyeleri ile uygun sosyal etkileşim sergileyecek, bakım uygulamalarına katılımda istekli olacak.

\section{Hemşirelik girişimleri:}

- Hasta bireye ismi ile hitap edilerek, kısa, basit cümleler ile yavaş konuşularak ve aktif bir şekilde dinlenerek öfke, güçsüzlük vb. hislerini ifade etmesine olanak sağlayacak ortam yaratılır,

- Sosyal etkileşimleri ve diğer aktivitelerinde güçlü yönleri ortaya konarak, doğru davranışları onaylanarak pozitif geribildirimler ile cesaretlendirilir,

- Halüsinasyon ve sanrılarının nedeni anlayacağı bir biçimde açıklanarak, hastanın gerçeğe dönmesi sağlanır (Carpenito-Moyet 2012; Townsend 2011).

\section{Uyku Örüntüsünde Bozulma}

Tanımlayıcı özellikler: Uykuya dalmakta ve uyumada güçlük, uyanırken ya da gün boyunca yorgunluk, ajitasyon, gün boyunca uyuklama, irritabilite, uykulu bir görünümün varlığı.

Illişkili faktörler: Sedatif ilaçların kullanımı sonucu gündüz uyuma, gündüz aktivitelerin yetersizliği, ağrı ve/veya korku, depresyon ve anksiyete, aşırı hiperaktivite, çevresel değişimler, sirkadiyen ritm değişiklikleri.

Amaç/ Beklenen hasta sonuçlarl: Hastanın, dinlenme ve aktiviteleri arasında optimal bir denge olacak, hastanın genel durumuna uygun ise gündüzleri uyanık olacak ve aktivitelere katılacak, geceleri uyuyacak, uyku getirici teknikleri tanımlayacak ve uyguladığı görülecek.

\section{Hemşirelik girişimleri:}

- Gürültü azaltılır, bakım uygulamaları gündüz saatlerinde yapılır,

- Gece 1şık azaltılarak, gündüz aydınlık bir ortam sağlanır, 
- Rahat bir uyku ve dinlenmenin sağlanabilmesi için, yaşam aktivitelerini sürdürmesi desteklenir ve hasta ile birlikte gündüzleri aktivite planı oluşturulur,

- Hasta bireyin anksiyetesini gidermeye yönelik; yalnız bırakmama, sessizliği kullanma, dokunma, ağlamaya izin verme gibi terapötik yaklaşımlar kullanılarak hastanın korku ve endişelerini anlatması için firsat verilir (Carpenito-Moyet 2012; Stuck ve ark. 2011).

\section{Travma Riski}

İlişkili faktörler: Bilinç bulanıklığına bağlı çevredeki tehlikelerin farkında olmama, stres, alkol ve benzerlerine bağlı hatalı yargılama, ajitasyon, irritabilite, halüsinasyon ve sanrilar.

Amaç/ Beklenen hasta sonuçlarl: Hasta travma deneyimlemeyecek.

Hemşirelik girişimleri:

- Hastanın dezoryantasyon ve konfüzyon düzeyi tanılama araçları ile belirli aralıklarla değerlendirilir,

- Hasta sürekli gözlem altında tutulur ve davranışları izlenir,

- Karyola kenarlıkları kaldırılır,

- Ajitasyon halinde terapötik iletişim teknikleri kullanılarak hasta sakinleştirilir,

- Hasta bireye ismi ile hitap edilir, tarih ve saatin ne olduğu, şu anda nerede olduğu vb. konularda bilgi verilerek hastanın yere, zamana ve kişiye oryantasyonu sağlanır,

- Çevresinden zarar verebilecek objeler kaldırılır,

- Bütün girişimlere rağmen hastada travma riski artar ise fiziksel kısıtlama uygulanır, ancak bu girişim en son tercih edilmeli ve hasta birey sakinleştiğinde k1sitlama sonlandırılmalıdır (Carpenito-Moyet 2012; Townsend 2011).

\section{Uygulama}

Bakım planında belirlenen hemşirelik girişimleri gözden geçirilir ve bireysel gereksinimler doğrultusunda gerekli uyarlamalar yapılır. Girişimler sırasında hastanın onuru ve gizliliği korunur, mümkün olduğunca uygulamalara katılımı sağlanır ve uygulama sırasında hastanın yanıtları değerlendirilerek kaydedilir. Bununla birlikte deliryum açısından risk oluşturan; fazla gürültü, ses, 1şı/aydınlatma gibi çevresel faktörleri en aza indirecek önlemler sürdürülür. Hastanın çevresinden gereksiz araç gereç, aletler kaldırılarak ortamın karmaşasından kaynaklanan uyaranlar kontrol altına alınır (Carpenito-Moyet 2012; Stuck ve ark. 2011; Townsend 2011).

\section{Değerlendirme}

Uygulanan hemşirelik girişimleri ile planlama aşamasında belirlenen amaç/ beklenen hasta sonuçlarına ulaşı1ıp ulaşılmadığı, dolayısı ile sorunun durumu değerlendirilir. Sorun devam ediyor ise nedenini araştırmak üzere sürecin tüm aşamaları gözden geçirilir ve belirlenen gereksinimler doğrultusunda bakım planlanında gerekli değişiklikler yapılır (Acaroğlu ve ark. 2012).

\section{SONUÇ VE ÖNERILER}

Sonuç olarak, yoğun bakım ünitesinde yatan hastalar için deliryumun sık karşılaşılan ve yaşamsal riskler oluşturabilen bir sorun olduğu göz önünde bulundurulmalı ve hastalar üniteye kabulünden itibaren bu aç1dan değerlendirilmelidir. Değerlendirmede, bireysel risk faktörleri kadar çevresel risk faktörleri de dikkate alınmalı ve elde edilen veriler doğrultusunda sorunlar belirlenerek uygun hemşirelik bakımı planlanmalı, uygulanmalı ve bakımın sonuçları değerlendirilmelidir.

\section{KAYNAKLAR}

Acaroğlu, R., Şendir, M., Kaya, H. (2012). Hemşirelik süreci. Babadağ, K., Aştı, T. A. (Eds.). Hemşirelik Esasları Uygulama Rehberi. İstanbul Tıp Kitabevi, İstanbul, 8-20.

Akıncı, S. B., Şahin, A. (2005). Yoğun bakımda deliryum. Yoğun Bakım Dergisi, 5(1): 26-35.

Ateş, A. (2012). Yoğun bakım ünitesinde hemşirelik tanılaması ile deliryum riskinin belirlenmesi. Yayınlanmamış Yüksek Lisans Tezi, İstanbul Üniversitesi Sağlık Bilimleri Enstitüsü, İstanbul.

Bruno, J. J., Warren, M. L. (2010). Intensive care unit delirium. Crit Care Nurs Clin North Am, 22(2): 161-178. 
Burge, D., Kent, W., Verdon, J., Voogt, S., Haines, H. M. (2010). Nurse practitioners are well placed to lead in the effective management of delirium. Aust J Adv Nurs, 28(1): 67-73.

Carpenito- Moyet, L. J. (2012). Hemşirelik Tanıları El Kitabı. Çeviren: F. Erdemir, 13. basım, Nobel Tıp Kitabevleri, İstanbul.

Cole, M. G. (2004). Delirium in elderly patients. Am J Geriatr Psychiatry, 12(1): 7-21.

Conley, D. M. (2011). The gerontological clinical nurse specialist's role in prevention, early recognition, and management of delirium in hospitalized older adults. Urol Nurs, 31(6): 337-343.

Day, J., Higgins, I., Keatinge, D. (2011). Orientaring strategies during delirium: Are they helpfull? J Clin Nurs, 20: 3285-3294.

Derby, S. (2011). Assessment and management of delirium in the older adult with cancer. Clinical Journal of Oncology Nursing, 15(3): 247-250.

Devlin, J. W. ve ark. (2008). Assessmet of delirium in the intensive care unit: Nursing practices and perceptions. Am J Crit Care, 17(6): 555-567.

Ely, E. W. ve ark. (2001). The impact of delirium in the intensive care unit on hospital length of stay. Intensive Care Med, 27: 1892-1900.

Ely, E. W. ve ark. (2004). Current opinions regarding the importance, diagnosis, and management of delirium in the intensive care units: A survey of 912 healthcare professionals. Crit Care Med, 32(1): 106-112.

Flagg, B., McDowel, S., Buelow, J. M. (2010). Nursing identification of delirium. Clin Nurse Spec, 24(5): 260-266.

Fong, T. G., Tulebaev, S. R., Inouye, S. K. (2009). Delirium in elderly adults: Diagnosis, prevention and treatment. Nat. Rev. Neurol, 5: 210-220.

Krahne, D., Heymann, A., Spies, C. (2006). How to monitor delirium in the ICU and why it is important. Clin Effect Nurs, 9(3): 269-279.
Küçük, L., Kaya, H. (2011). Koroner yoğun bakım sürecinde yaşanan psikiyatrik bir durum: Deliryum ne kadar tanıyoruz? Maltepe Üniversitesi Hemşirelik Bilim ve Sanatı Dergisi, 4(1): 161-166.

Nursing management of delirium. (2013). http://nursingplanet. com/pn/nursing management delirium.html (04.02.2014).

Rice, K. L. ve ark. (2011). Nurses' recognition of delirium in the hospitalized older adult. Clin Nurse Spec, 25(6): 299-311.

Rompaey, B. V. ve ark. (2009). Risk factors for delirium in intensive care patients: A prospective cohort study. Crit Care, 13(3): 77-89.

Schuurmans, M. J., Duursma, S. A., Shortridge- Baggett, L. M. (2001). Early recognition of delirium: Review of the literature. $J$ Clin Nurs, 10: 721-729.

Stuck, A., Clark, M. J., Connelly, C. D. (2011). Preventing intensive care unit delirium: A patient-centered approach to reducing sleep disruption. Dimens Crit Care Nurs, 30(6): 315-320.

Tabet, N., Howard, R. (2009). Non-pharmacological interventions in the prevention of delirium. Age Ageing, 38(4): 374-379.

Townsend, M. C. (2011). Nursing Diagnosis in Psychiatric Nursing: Care Plans and Psychotropic Medications. 8. basım, F. A. Davis Company, Philadelphia, https://ryanzer.files.wordpress. com/2012/03/nursing-diagnoses-in-psyciatric.pdf (10.01.2014)

Truman, B., Ely, E. W. (2003). Monitoring delirium in critically ill patients: Using the confusion assessment method for the intensive care unit. Crit Care Nurse, 23: 25-35.

Weber, J., Kelley, J. (2010). Assessing mental status\& psychosocial developmental level. Weber, J., Kelley, J. (Eds.). Health Assessment In Nursing. 4. basim, Wolters Kluwer Health/ Lippincott Williams \& Wilkins, 55-76.

Webb, J. M., Carlton, E. F., Geehan, D. M. (2000). Delirium in the intensive care unit are we helping the patient? Crit Care Nurs $Q$, 22(4): 47-60.

Webster, J. (2011). Improving care for people with dementia in acute hospital: The role of person-centred assessment. Qual Ageing Older Adults, 12(2): 86-94. 